\section{Keine Zeit zum Tassenspülen}

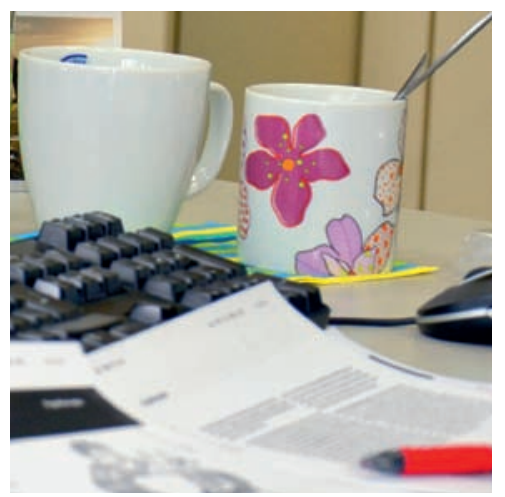

_ Eine halbe Tafel Schokolade auf dem Schreibtisch, Unmengen Papierstapel, eine Flasche Selters und zwei schmutzige Kaffeetassen ... Kurz bevor die ergopraxis in den Druck geht, hat sich mein Schreibtisch mal wieder zur Chaoslandschaft verwandelt. Alles dreht sich nur um das aktuelle Heft. Schnell noch eine Mail, dann der wichtige Anruf bei einer Autorin. Haben Sie das Foto in einer besseren Auflösung? Dann spurte ich in die Grafikabteilung: Diese Abbildung enthält noch Fehler. Kann der Zeichner das bis morgen verbessern? Zurück im Büro werfe ich einen Blick in meinen Plan. Zwei Artikel müssen jetzt noch in die letzte Korrektur. Das sollte ich schaffen, bevor ich in die nächste Besprechung gehe.

_ Irgendetwas reizt mich an dieser allmonatlichen Spannung. Der Blick konzentriert sich auf die momentan wichtigsten Dinge - alles andere wird ausgeblendet. Wie könnte ich sonst die schmutzigen Kaffeetassen so erfolgreich ignorieren? Aber nicht nur ich: Das ganze Team arbeitet unter Hochdruck, damit jeder Beitrag im Heft stimmig, fundiert und gut lesbar wird.

_ Erst wenn wir alle Artikel fertig für die Druckerei haben, verliert sich die Hektik, und ein normales Tempo kehrt ein. Dann erst fallen mir meine Tassen auf, die ich auch gleich spüle.

_ Vor vier Jahren fing der Trubel an: Im Mai 2008 brachten wir die erste Ausgabe der ergopraxis auf den Markt. Vier Jahre, die zeigen, dass sich die Mühe lohnt! Wir hoffen, wir haben auch dieses Mal Ihren Geschmack getroffen und spannende Beiträge für Sie augewählt. Viel Freude mit dieser Geburtstagsausgabe wünscht Ihnen von Herzen die ergopraxis-Redaktion.

Ihre

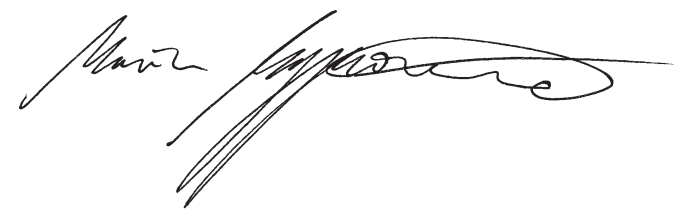

\section{ZU GEWINNEN}

Kurs

Spiegeltherapie und

mentales Training bei

chronischen Schmerzen

Seite 45

Bücher

3-mal „Alter spielt keine Rolle, außer man ist ein

Rotwein"

Seite 10

2-mal „Schmerzen verstehen"

Seite 29

3-mal „Als die

Kaffeemühle streikte“

Seite 33

Und außerdem...

1 Handbalance Frosch

Seite 21

\section{Wir feiern vier Jahre} ergopraxis ...

... und verlosen einen Gutschein von Wehrfritz. Der Gewinner kann sich Spielwaren oder Therapiematerialien im Wert von

100 Euro

aussuchen.

Klicken Sie bis

zum 8.6.2012

unter www.thieme.de/ergoonline > „ergopraxis“ > "Gewinnspiel“ auf das Stichwort „Geburtstag“.

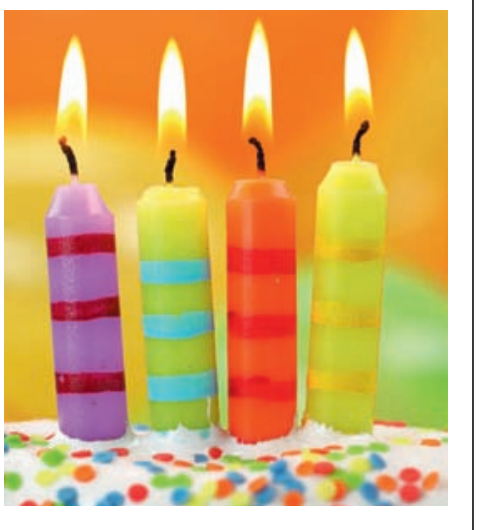

